\title{
Optimization of metallic powder filaments for additive manufacturing extrusion (MEX)
}

\author{
Fábio Cerejo $^{1,2}$ (D) $\cdot$ Daniel Gatões $^{2} \cdot$ M. T. Vieira ${ }^{2}$ \\ Received: 26 January 2021 / Accepted: 1 April 2021 / Published online: 25 May 2021 \\ (C) The Author(s) 2021
}

\begin{abstract}
Additive manufacturing (AM) of metallic powder particles has been establishing itself as sustainable, whatever the technology selected. Material extrusion (MEX) integrates the ongoing effort to improve AM sustainability, in which low-cost equipment is associated with a decrease of powder waste during manufacturing. MEX has been gaining increasing interest for building 3D functional/structural metallic parts because it incorporates the consolidated knowledge from powder injection moulding/ extrusion feedstocks into the AM scope-filament extrusion layer-by-layer. Moreover, MEX as an indirect process can overcome some of the technical limitations of direct AM processes (laser/electron-beam-based) regarding energy-matter interactions. The present study reveals an optimal methodology to produce MEX filament feedstocks (metallic powder, binder, and additives), having in mind to attain the highest metallic powder content. Nevertheless, the main challenges are also to achieve high extrudability and a suitable ratio between stiffness and flexibility. The metallic powder volume content (vol.\%) in the feedstocks was evaluated by the critical powder volume concentration (CPVC). Subsequently, the rheology of the feedstocks was established by means of the mixing torque value, which is related to the filament extrudability performance.
\end{abstract}

Keywords MEX $\cdot$ Filament $\cdot$ Additive manufacturing $\cdot$ Mixing torque $\cdot$ Austenitic stainless steel $(316 \mathrm{~L})$

\section{Introduction}

Additive manufacturing (AM) of powder metals and metal alloys is an unavoidable area for Industry 4.0 owing to its potential to address some of the most significant industrial challenges in the twenty-first century concerning parts/system/devices processing [1]. The rising trend to select AM processes is based on new design approaches, the ability to create near net shape 3D objects, cloud access to manufacturing, shorter time-to-market, product customization, and circular economy [2]. Among other factors, the possibility of merging cost savings and new part properties and features that are

Fábio Cerejo

fcerejo@ipn.pt

$\triangle$ Daniel Gatões

daniel.gatoes@uc.pt

1 IPN - LED\&MAT - Instituto Pedro Nunes, Laboratório de Ensaios, Desgaste e Materiais, Rua Pedro Nunes, 3030-199 Coimbra, Portugal

2 University of Coimbra, CEMMPRE - Centre for Mechanical Engineering, Materials and Processes, Department of Mechanical Engineering, Rua Luís Reis Santos, 3030-788 Coimbra, Portugal impossible to obtain using traditional manufacturing technologies is the largest benefit of AM. This manufacturing paradigm, concerning powder metal AM, has attracted significant interest over the past few years, where AM direct methods (e.g. Selective Laser Melting, Electron Beam Melting, etc.) established themselves as technologies for functional/ structural metallic parts, with several components approved by ISO and ASTM standards in industries such as aerospace and automotive [3]. However, these processes have several drawbacks, the high-power source that can promote microand macroscopic defects in metallic parts due to the multiple thermal treatments of the deposited layers; material range, due to the energy-matter interaction that limits the powder characteristics, like reflectivity and conductivity; and significant powder wastes during manufacturing and handling hazard. Besides, the high cost of direct AM equipment is one of the major obstacles [4-10].

Material extrusion (MEX) and binder jetting (BJ) [11] are already well-established technologies with market acceptance for the AM. Based on this successful background, MEX and BJ have been investigated with the aim to produce metallic and ceramic functional/structural components through shaping, debinding, and sintering (SDS). In these indirect AM processes, 
1

Materials Selection

Metallic powder

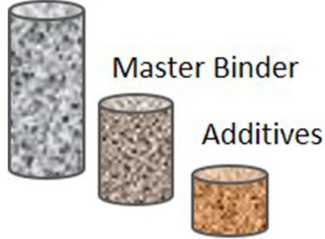

2

Mixing
3

Filament Fabrication
4

3D Shaping
5

Debinding

and
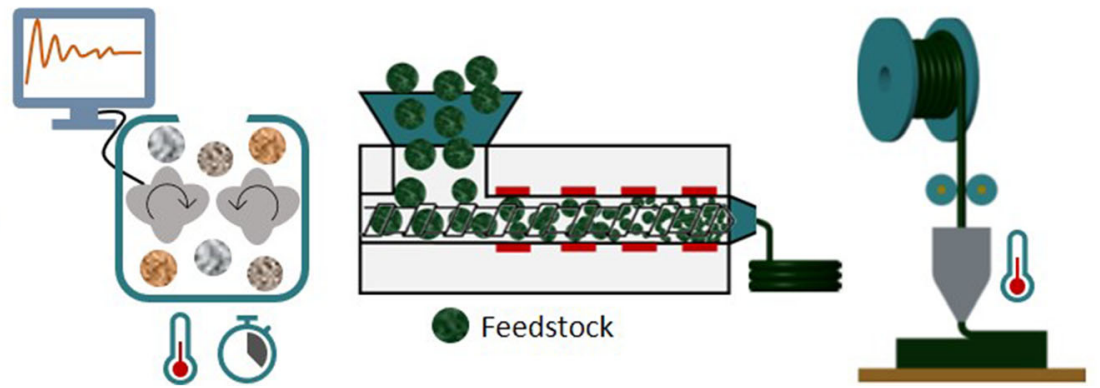
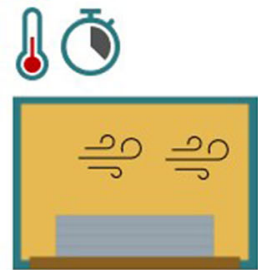

Fig. 1 MEX manufacturing route through the shaping, debinding, and sintering (SDS) process

unlike direct methods, the material processability is independent of the power source, which makes the production of functionally graded materials feasible [12]. Regarding shaping, BJ and MEX differ from each other and are often complementary technologies, since resolution, the optimal number of parts per production, the necessity of supports, material, and equipment costs are unique for each process. In BJ, the binder droplets are selectively deposited to interact with powder particles, which present new challenges not associated with MEX, such as powder/binder wettability; binder vertical migration, since layer height affects the penetration depth of the binder, through time and capillary force; and binder saturation that must be finetuned, as well as droplet size and dispensing frequency. However, the metallic powder is fed independently of the binder, which makes the rheological properties not as hard to control as it happens with MEX, which is beneficial to achieve the highest vol.\% of metallic powder and less binder content in the shaped 3D object $[12,13]$. Even though both technologies differ in what concerns the powder-binder processability, they also face the same challenges, such as optimizing debinding heating profiles to degrade the polymer is time-consuming; possible undesired reactions from residual polymer ash that could affect the final properties; and porosity, since both technologies do not have high pressures that promote the highest final part densification $[12,14]$.

The present study is focused on the MEX technology, which was initially referred to as the fused deposition of metals (FDMet), and then as Fused Filament Fabrication (FFF) or as Metallic Fused Filament Fabrication $\left(\mathrm{MF}^{3}\right)$ [15]. MEX is based on the fused deposition modelling $\left(\mathrm{FDM}^{\mathrm{TM}}\right)$ technology commercialized by Stratasys Inc. for polymers and waxes, where the filament is composed of a mixture of a high volume content (vol.\%) of metallic powders with organic constituents [16]. MEX is suitable for manufacturing geometrical complex metal parts in conjunction with post-shaping steps, such as debinding and sintering [17].

The processing by MEX technology consists of 5 stages (Fig. 1), as follows: Stage 1, materials selection; Stage 2, mixing $(1+2=$ powder material extrusion feedstocks fabrication); Stage 3, feedstock extrusion (filament); Stage 4, 3D part/device built layer-by-layer (green) from extruded filament; and Stage 5, binder removal (debinding) and subsequent consolidation of metallic powder particles (sintering). The first two stages are fundamental to attain an appropriate viscosity and an excellent balance between flexibility and stiffness of the filament associated with the highest content
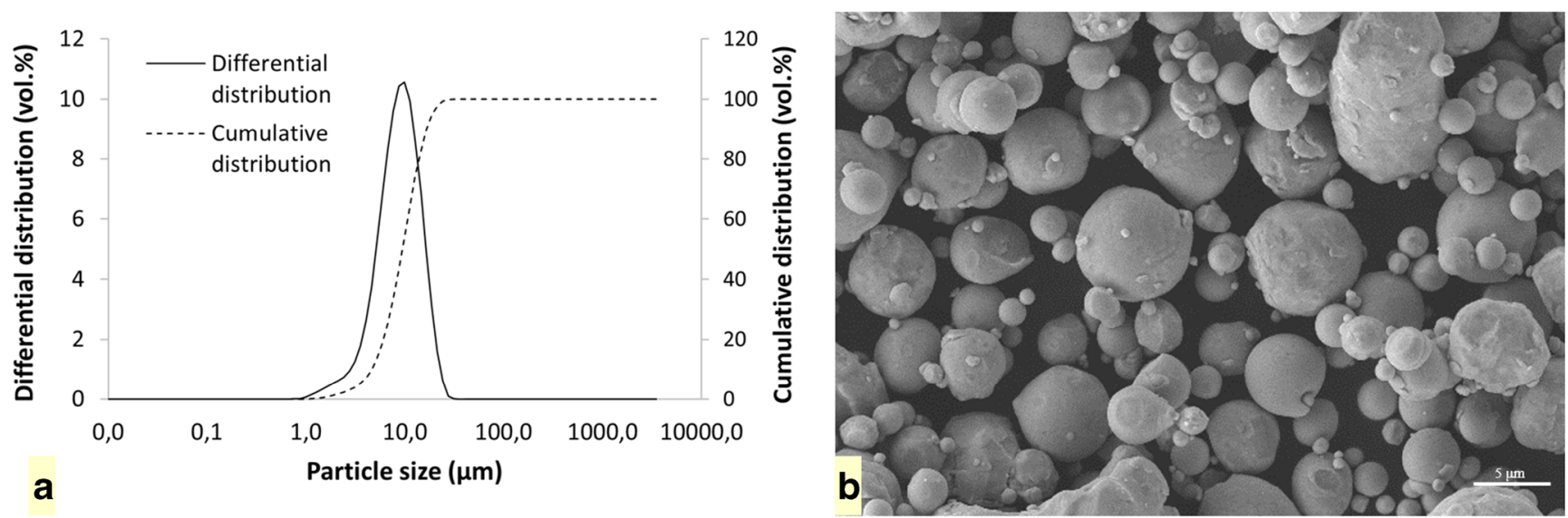

Fig. 2 a Particle size distribution (Malvern Mastersizer 2000) and b powder shape (SEM analysis, SE) of the SS 316L powder 
(\%vol) of metallic powders and a subsequent homogeneity (chemical and dimensional) needed to attain low porosity and excellent quality of the parts/devices.

High-quality structural/functional parts/systems/devices through an SDS process must include efforts to achieve the highest content (vol.\%) of the metallic powder particles possible in the feedstock within the steady-state regime but always taking into account the final mixing torque value. This becomes a significant challenge in MEX because the mixture must be manufactured in a filament form. Based on these assumptions, there are a few available studies in the bibliography. Agarwala et al. obtained stiff and straight filaments from feedstocks with 60 vol. $\%$ 17-4PH grade stainless steel (SS) [18]. Kukla and Gutierrez et al. [19, 20] used 55 vol.\% SS 316L and 17-4PH; Godec et al. [10] also selected 55 vol.\% SS 316L, as well as Burkhardt et al. [21]. Anderson et al. [22] produced SS 316L grade filaments with 55 vol.\%; Kurose et al. [23] used SS 316L grade filaments with 60 vol.\%. Gloeckle et al. [24] performed an extensive study on the printability of Ti-6Al-4V filaments with up to $60 \mathrm{vol} . \%$ of inorganic material, and Singh et al. [15] used the same Ti-6Al-4V with 59 vol.\%. BASF SE® has a commercially available SS $316 \mathrm{~L}$ filament with a metallic powder content lower than 60 vol.\% [25].

The mechanical performance of MEX metallic filaments has been a major limitation for increasing the ratio between inorganic and organic constituents since high powder concentration can lead to poor extrudability, where the filament becomes too brittle to be handled. A balance between stiffness and flexibility must be guaranteed to promote filament printability $[15,19]$.

The focus of the present study is to develop filaments with the highest metallic powder volume content (>50 vol.\%) that link the primary MEX filament requirements to a suitable viscosity and mechanical behaviour. The selection of the highest content of metallic powder was evaluated by critical powder volume concentration (CPVC) methodology [26-28]. This procedure aims to promote the highest part green density, which is essential for maintaining the part shape integrity after debinding and sintering.

The present study aims to contribute, whatever the powder selected, to high-quality filaments for MEX technology, that is in conjunction with binder jetting technology, the future of $\mathrm{AM}$ of functional/structural 3D metallic objects.

Table 1 SS 316L powder characteristics

\begin{tabular}{lllll}
\hline$d_{10}[\mu \mathrm{m}]$ & $d_{50}[\mu \mathrm{m}]$ & $d_{90}[\mu \mathrm{m}]$ & $\mathrm{SSA}^{*}\left[\mathrm{~kg} / \mathrm{m}^{2}\right]$ & $\rho\left[\mathrm{kg} / \mathrm{m}^{3}\right]^{* * *}$ \\
\hline 4.63 & 9.43 & 16.60 & 786 & $7896 \pm 30.2$ \\
\hline
\end{tabular}

*Specific surface area

**Density

\section{Materials and methods}

\subsection{Characterization techniques}

The characterizations of the powders, feedstocks, and filaments were performed through the following techniques: laser diffraction to measure the particle size (Malvern Mastersizer 2000, Malvern Instruments Ltd, Worcestershire, UK) according to ISO 13320:2009(E); helium pycnometry to measure the density, based on the mean of five runs for each specimen (Micromeritics AccuPyc 1330, Micromeritics Instrument Corporation, Norcross, GA, USA); scanning electron microscopy (SEM) to analyse the morphology and shape factor (FEI Quanta 400FEG, FEI Europe BV, Eindhoven, The Netherlands) $\mathrm{x}$-ray diffraction (XRD) according to EN 13925:2003, to identify the phases (Philips X'Pert, cobalt radiation $\lambda_{\mathrm{k} \alpha 1}=0.1789 \mathrm{~nm}$ and $\lambda_{\mathrm{k} \alpha 2}=0.1793 \mathrm{~nm}$, BraggBrentano geometry, Philips, Eindhoven, Netherlands); and TGA to analyse the weight variation kinetics (TGA Q500 V20.13, TA Instruments, DE, USA). The filament was micro-CT (X-ray micro computed tomography) scanned using a Bruker SkyScan 1275 (Bruker, Kontich, Belgium). An acceleration voltage of $80 \mathrm{kV}$ and a beam current of $125 \mu \mathrm{A}$ was set while using a $1-\mathrm{mm}$ aluminium filter and step-and-shoot mode. Pixel size was set to $6 \mu \mathrm{m}$, and random mode was used. In total, 1056 projection images were acquired at $0.2^{\circ}$ angular step with 5 frames average per step using an exposure time of $46 \mathrm{~ms}$. The micro-CT images were reconstructed with the dedicated manufacturer software.

A three-point flexural test of each filament was performed five times using SHIMADZU-EZ-LX (Shimadzu Corp., Kyoto, Japan) equipment with a load capacity of $500 \mathrm{~N}$. The load was applied to the specimen at a rate of $0.5 \mathrm{~mm} / \mathrm{min}$ with a span length of $20 \mathrm{~mm}$.

3D prototype geometries were measured with Focus Variation Microscopy (FVM) using Alicona InfiniteFocusG4 (Alicona Imaging; Graz, Austria). Hardness measurements, according to ISO 6507-2:2018, were performed with a Shimadzu

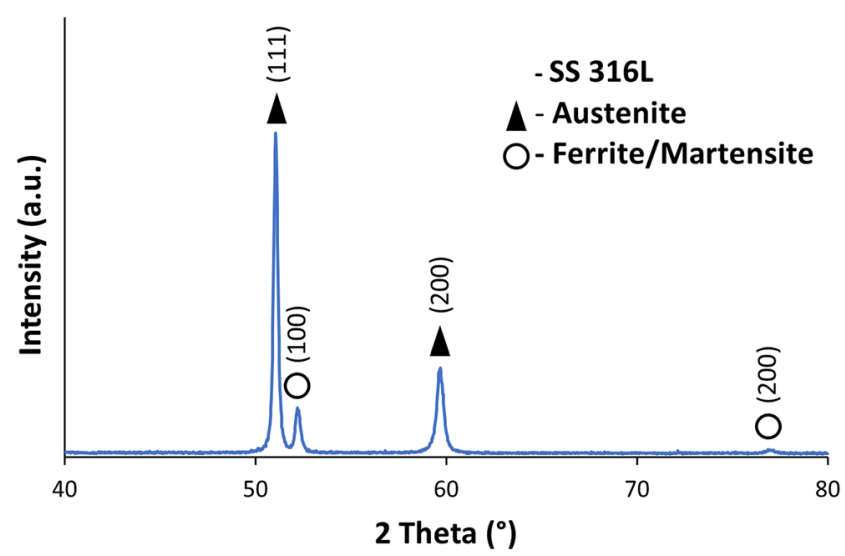

Fig. 3 SS 316L XRD diffractogram; $\lambda$ Co $=0.1789$ nm (Philips X'Pert) 
Table 2 Densities of the binder and additives measured with a helium pycnometer

(Micromeritics AccuPyc 1330)

\begin{tabular}{llllll}
\hline & M1 & TPE & ULD-PE & $\mathrm{S}^{\dagger}$ & $\mathrm{P}^{*}$ \\
\hline Density $\left[\mathrm{kg} / \mathrm{m}^{3}\right]$ & $970 \pm 1$ & $1028 \pm 12.2$ & $9144 \pm 1.5$ & $983 \pm 1$ & $965 \pm 0.6$ \\
\hline
\end{tabular}

$\mathrm{S}^{\dagger}$ Surfactant

$\mathrm{P}^{*}$ Plasticizer
HMV microhardness tester (Shimadzu Corp., Kyoto, Japan). For each measurement, a load of $9.8 \mathrm{~N}$ was applied for $15 \mathrm{~s}$ by a Vickers indenter.

\subsection{Metallic powder, binder, and additives}

The set material for this study was austenitic stainless steel 316L (SS 316L) since it is one of the most studied materials in AM. This material can be a good standard for the methodology to be established by the present work and extrapolated to other metallic alloys [29].

The characteristics of the selected powders were studied using the 4S's methodology (size and size distribution, shape, and structure). The particle size is $d_{50}=9.43 \mu \mathrm{m}$. Figure 2 shows the particle size distribution (a) and particle shape factor (b). Shape factor was close to 1 for the nitrogen-atomized SS 316L powders (Sandvik Osprey Ltd., Neath, UK).

Table 1 summarizes the powder characteristics.

The X-ray diffractogram (Fig. 3) of the SS 316L powder exhibited a biphasic character, where the major phase was austenite (ICDD 33-0397). However, other peaks with low $\mathrm{I} / \mathrm{I}_{0}$ were present, which can be indexed as (100), (200) that are typical of ferrite/martensite (ICDD 87-0722). The cooling stress could contribute to the evolution of the austenite phase into martensite. Nevertheless, nitrogen atomizing results in lower stress in the particles than those from water atomizing, where martensite is more prevalent for a similar powder [30].

In the present study, the organic constituents of the feedstocks were divided into two primary groups: master binder and additives; the last one includes the backbone and surfactant/plasticiser. The selected master binder (M1) was a commercial-grade (Atect Corp., Shiga, Japan) that is a mixture of polyolefin waxes and $>60 \mathrm{wt}$. \% of polyoxymethylene (POM). Although POM is included, this binder is commercialized as a thermal-only debinding and previous studies with this binder shown that no carbonaceous residues remained on the final parts. The thermoplastic elastomer (TPE), as well as an ultra-low density polyethylene (ULD-PE), was used for the backbone, and a surfactant (stearic acid (S †)) and an external plasticizer $(\mathrm{P} *)$ were used as additives. Density of master binder and additives (Table 2) was performed to support the theoretical calculations of the volume of these constituents in the feedstock, which is further compared with the practical results (TGA analysis).

\subsection{Filament production}

The vol.\% of each organic component in the feedstock was tailored to achieve the proper filament properties for MEX (rheology and flexibility/stiffness balance). The CPVC and

Table 3 Filament feedstocks

\begin{tabular}{|c|c|c|c|c|c|c|c|}
\hline \multirow[t]{2}{*}{ Feedstock } & \multirow[t]{2}{*}{ Master binder } & \multicolumn{4}{|l|}{ Additives } & \multicolumn{2}{|l|}{ Powder } \\
\hline & & Backbone & Backbone content (vol.\%) & $\mathrm{S}^{\dagger}$ or $\mathrm{P}^{*}$ & $\mathrm{~S}^{\dagger}$ or $\mathrm{P}^{*}(\operatorname{vol} . \%)$ & SS 316 L content (vol. \%) & Particle size $d_{50}(\mu \mathrm{m})$ \\
\hline F01 & M1 & - & - & - & - & 60 & 6.85 \\
\hline F02 & M1 & TPE & $Y$ & - & - & 60 & 6.85 \\
\hline F03 & M1 & TPE & $X$ & $\mathrm{~S}^{\dagger}$ & 5 & 60 & 6.85 \\
\hline F04 & M1 & TPE & $X+5$ & $\mathrm{~S}^{\dagger}$ & 5 & 60 & 6.85 \\
\hline F05 & M1 & TPE & $X+10$ & $\mathrm{~S}^{\dagger}$ & 5 & 60 & 6.85 \\
\hline F06 & M1 & TPE & $X$ & $\mathrm{P}^{*}$ & 5 & 60 & 6.85 \\
\hline F07 & M1 & TPE & $W$ & $\mathrm{P}^{*}$ & 10 & 60 & 6.85 \\
\hline F08 & M1 & ULD-PE & $X$ & $\mathrm{P}^{*}$ & 5 & 60 & 6.85 \\
\hline
\end{tabular}

*The exact ratio of master binder/backbone in the feedstock will be kept confidential. $Y, X$, and $W$ represent the different amounts of backbone (vol.\%). $X=Y-2.5$ vol. $\%$; (1/2 of S/P content: 5 vol. $\%)$.

$W=Y-5$ vol. $\%$; (1/2 of F07 plasticiser (P) content: 10 vol. $\%)$.

$\mathrm{S}^{\dagger}$, Surfactant

$\mathrm{P}^{*}$, Plasticiser 
Fig. 4 TGA curves of the SS 316L, M1, TPE, and M1 + TPE under an $\mathrm{N}_{2}$ atmosphere

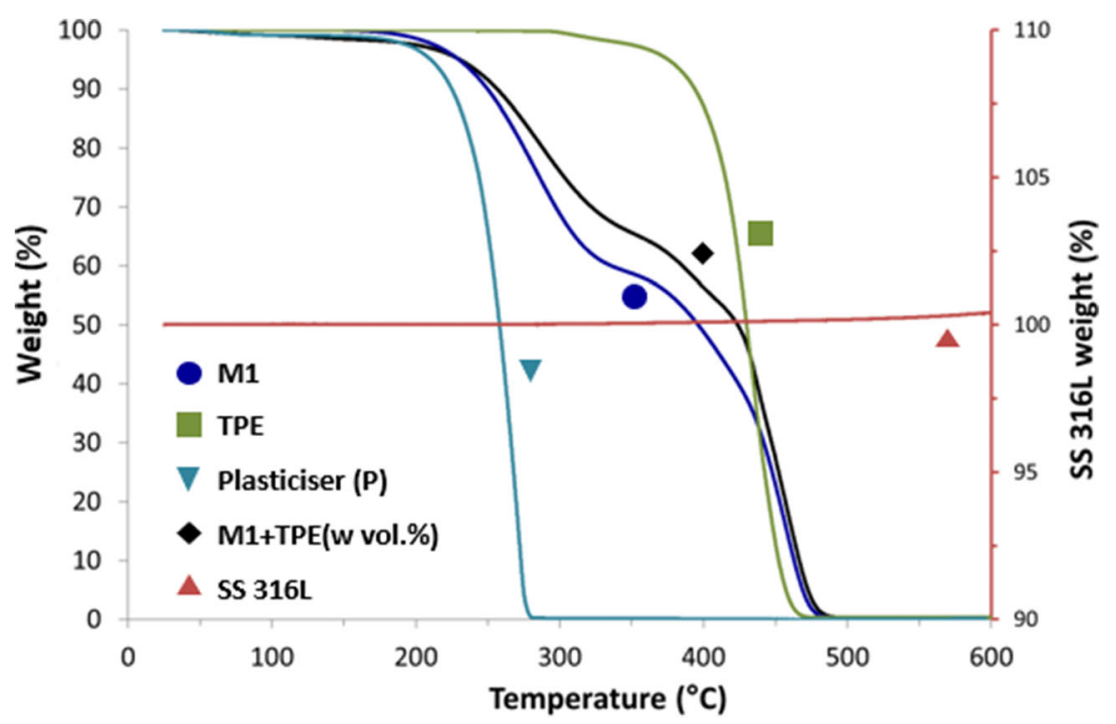

feedstock optimization was performed with a torque rheometer (Plastograph ${ }^{\circledR}$ Brabender W 50, Brabender GmbH \& Co. $\mathrm{KG}$, Duisburg, Germany) that evaluates the torque variation as a function of the powder composition. The temperature inside the $38.5 \mathrm{~cm}^{3}$ mixing chamber of $180{ }^{\circ} \mathrm{C}$ was selected together with $30 \mathrm{rpm}$ blades rotation speed, taking into account previous work with the same master binder [31]. For the CPVC evaluation, an increment of 1 vol.\% powder content was made approximately every $10 \mathrm{~min}$ or after reaching a steady state. The backbone percentage was not higher than $30 \%$ of the total organic portion. Table 3 summarizes the different feedstock compositions (F01-F08, F03A, and F03B). Each formulation mixing torque value was evaluated from six independent measurements and done until a steadystate regime was achieved.

Small pellets of feedstocks were extruded into a filament form. Filament fabrication was performed in a single screw extruder (Brabender GmbH \& Co., Duisburg, Germany) with 5 heating zones. The temperature of the zones, from feeder to nozzle $(\varnothing 1.75 \mathrm{~mm})$, was set at $160,165,170,175$, and $180^{\circ} \mathrm{C}$. The screw rotation speed was set at $5 \mathrm{rpm}$. The filament was measured at multiple points to guarantee its dimensional accuracy throughout the filament fabrication process.

Instead of using catalytic debinding, thermal debinding was selected, which shows no carbonaceous residues present during sintering, consistent with previous studies with lowpressure injection moulding [31], thus voiding the nitric acid used for catalytic debinding. The thermogravimetric analysis highlights that all of the organic constituents of the feedstock fully degrade, during the debinding stage (Fig. 4).

The thermal cycles in this work were selected based on thermogravimetric analysis (TGA). The primary events in the master binder and backbone weight loss curves up to $600{ }^{\circ} \mathrm{C}$ (Fig. 4 and Table 4) were the isothermal plateaus during the debinding stage. The beginning and ending values were evaluated from the first derivative (DTG) of the respective curve. At $495^{\circ} \mathrm{C}$, the carbonaceous residue was close to 0 wt.\%.

Concerning the thermal oxidation of the as-received SS $316 \mathrm{~L}$ powder, TGA showed that it was quite stable up to $600{ }^{\circ} \mathrm{C}$ in an $\mathrm{N}_{2}$ atmosphere. An insignificant increase in the weight of the powder was noticeable above $500^{\circ} \mathrm{C}$. This is not
Table 4 Weight loss and degradation temperatures of the M1, TPE, and M1 + TPE

\begin{tabular}{lllll}
\hline Binder component & Degradation stage & Weight loss $[\%]$ & Onset $\left[{ }^{\circ} \mathrm{C}\right]$ & End $\left[{ }^{\circ} \mathrm{C}\right]$ \\
\hline M1 & 1st & 41 & 232 & 314 \\
& 2nd & 13 & 378 & 437 \\
& $3 \mathrm{rd}$ & 46 & 437 & 472 \\
TPE & 1 st & 2 & 300 & 327 \\
& 2nd & 98 & 408 & 454 \\
M1 TPE & 1st & 35 & 238 & 320 \\
& 2nd & 11 & 375 & 398 \\
& 3rd & 23 & 427 & 441 \\
& 4th & 31 & 450 & 475 \\
Plasticizer & 1st & 100 & 242 & 276 \\
\hline
\end{tabular}


Fig. 5 TGA curves of the filaments F03, F06, and F08 with 60 vol. $\%$ of SS $316 \mathrm{~L}$ powder under an $\mathrm{N}_{2}$ atmosphere

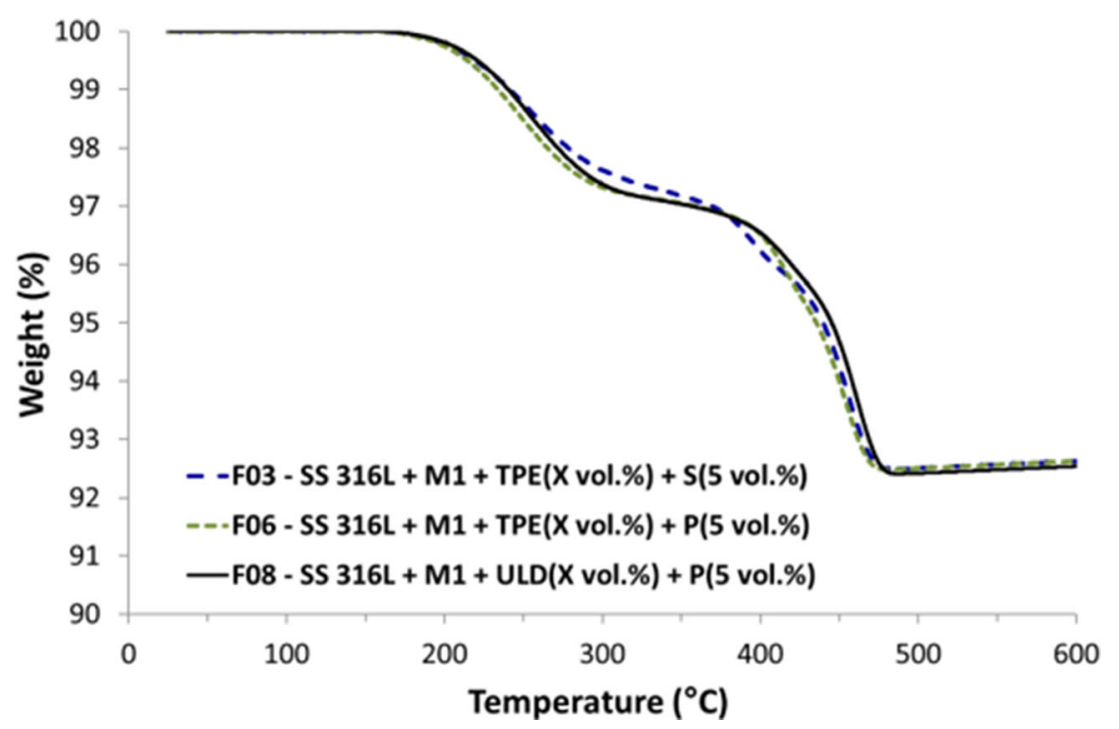

exclusively attributed to the TGA protective atmosphere type $\left(\mathrm{N}_{2}\right)$ because other studies show the same behaviour under an $\mathrm{Ar}+\mathrm{H}_{2}(5 \%)$ atmosphere $[30,32]$.

A significant difference was not detected in the debinding kinetics of the M1 and TPE as raw materials (Fig. 4) and as feedstocks constituents (Fig. 5) when mixed with 60 vol.\% of metallic powder. This is an indication that there are no undesired reactions among the feedstock constituents that could interfere in the debinding cycle.

Table 5 shows a comparison of the theoretical values against the final experimental values (wt.\%) of the feedstock filaments at $600{ }^{\circ} \mathrm{C}$ in order to illustrate the expected SS 316L weight (\%) after binder degradation based on the SS $316 \mathrm{~L}$ vol. $\%$ in the feedstock. The small deviation between theoretical and experimental values can be attributed to the experimental evaluation of the densities and can be assumed that the binder degradation was total.

\subsection{Printability}

Green specimens were built on a BQ Prusa I3 Hephestos 3D printer. Extruder nozzle temperature was maintained at

Table 5 TGA experimental vs theoretical weight reduction of filaments F03, F06, and F08

\begin{tabular}{lll}
\hline Feedstock & \multicolumn{2}{l}{ Metallic powder [wt.\%] } \\
\cline { 2 - 3 } & Experimental & Theoretical* \\
\hline F03 & $92.5 \pm 0.1$ & 92.4 \\
F06 & $92.5 \pm 0.1$ & 92.4 \\
F08 & $92.4 \pm 0.1$ & 92.4 \\
\hline
\end{tabular}

*Conversion from SS 316L 60 vol.\% $210^{\circ} \mathrm{C}$, extrusion speed was limited to $10 \mathrm{~mm} / \mathrm{s}$, and extrusion multiplier was set at 1.4. Layer height was set at $0.20 \mathrm{~mm}$, and the selected nozzle diameter was $0.40 \mathrm{~mm}$. A glass platform with a layer of glue was used, to promote part adhesion, since this $3 \mathrm{D}$ printer has no heated build plate feature.

\subsection{Debinding and sintering}

The heating rates for debinding and sintering were $1{ }^{\circ} \mathrm{C} / \mathrm{min}$ and $10{ }^{\circ} \mathrm{C} / \mathrm{min}$ up to the maximum temperatures of $600{ }^{\circ} \mathrm{C}$ and $1250{ }^{\circ} \mathrm{C}$, respectively, including several debinding isothermal holding times, based on the TGA results. The filaments and parts were debinded and sintered under $\mathrm{H}_{2}$ atmosphere at $4 \times 10^{-2} \mathrm{MPa}$.

\section{Results and discussion}

\subsection{Feedstock optimization}

\subsubsection{Evaluation of the critical powder volume concentration}

The evaluation of the CPVC in each feedstock was performed by recording the mixing torque to maximize the metal powder content (vol.\%), to promote higher green densities. Nevertheless, MEX feedstocks require overcoming new challenges (rheology and flexibility/stiffness balance) because the filament must be spooled, handled, and extruded through a small-diameter nozzle. Therefore, PIM feedstocks must be modified to be suitable for MEX, and the rheological behaviour of the new feedstock must be studied.

Torque values were recorded for the initial mixture of the master binder and additives F06 (M1 + TPE + P) with 50 vol.\% SS $316 \mathrm{~L}$ powder. The effect of 
Fig. 6 Torque as a function of time of the F06 feedstock at 180 ${ }^{\circ} \mathrm{C}$ with the incremental addition of 1 vol.\% of SS 316L

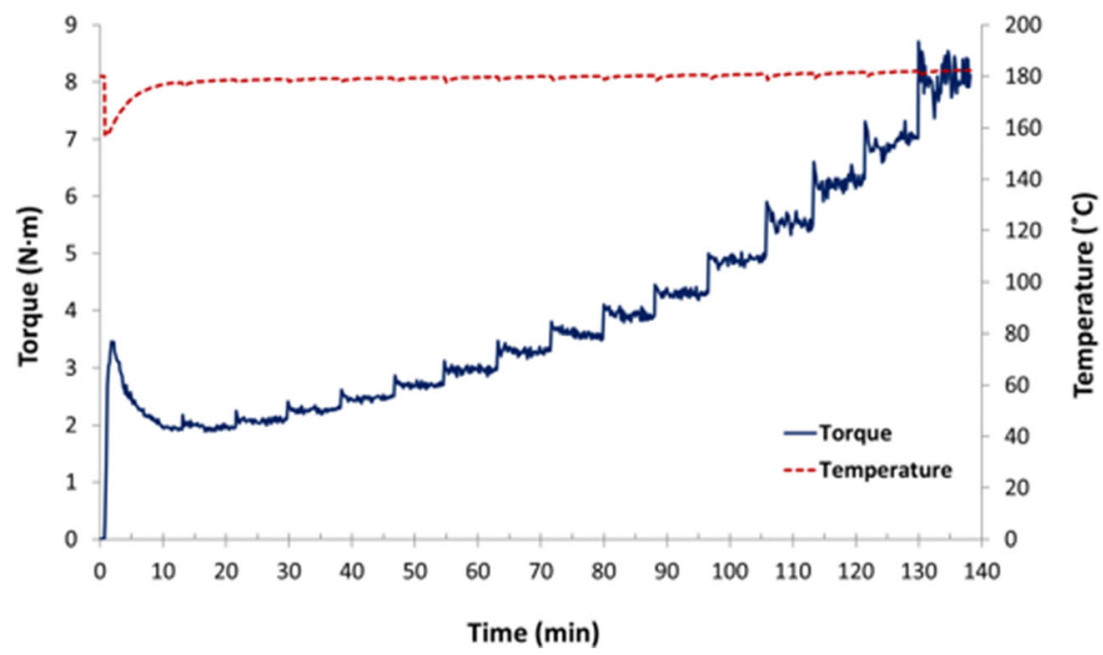

subsequent additions of metallic powder (1 vol.\%) on the torque value, shown at every peak from the 10min mark, was measured after attaining a steady-state regime for each percentage (Fig. 6). Based on this evaluation, the defined ratio of inorganic/organic vol. $\%$ among all studied feedstocks was maintained.

Figure 7 shows the torque values for the incremental additions of 1 vol.\% of SS 316L powder (50-65 vol.\%). Three linear regimes can be observed:

- The first regime includes up to 58 vol.\% of SS $316 \mathrm{~L}$ powder, and the torque variation between each addition is between 1.9 (50 vol.\%) and $3.5 \mathrm{~N} \cdot \mathrm{m}$ (58 vol.\%).

- In the second regime, at up to 62 vol. $\%$ of SS $316 \mathrm{~L}$ powder, the mixture rheology changes, which corresponds to a slightly higher slope than the first regime, and the maximum torque is $5.4 \mathrm{~N} \cdot \mathrm{m}$.

- The third regime, where the most significant variation occurs (62-65 vol.\%), reaches the highest mixing torque value $(8.1 \mathrm{~N} \cdot \mathrm{m})$. In this range, the mixing torque behaviour clearly becomes more unstable (cf. Fig. 7).
The CPVC should correspond to the interface torque value between the second and third regimes (point of intersection), which in the present study was 62 vol.\%. However, a great number of studies performed concerning the optimization of powder and binder feedstocks show that the torque value should not exceed 5 N.m for this specific torque rheometer (Plastograph® W 50), to attain the best rheological properties, in order to guarantee optimal processability [28, 33, 34].

Based on the CPVC evaluations (Figs. 6 and 7) and keeping in mind that the feedstock flowability to build the green part, through a $3 \mathrm{D}$ printer with a $0.4-\mathrm{mm}$ nozzle, is promoted by the filament (it acts like a piston through the $3 \mathrm{D}$ printer pull system) and not by a screw (high pressures), 60 vol.\% (torque value of 4.3 N.m) was selected as the metallic load for all studied feedstocks.

\subsubsection{Effect of additives in the feedstock}

In PIM, the binder generally promotes the best compromise between green integrity and flowability.
Fig. 7 Three different regimes of torque as a function of powder volume concentration (feedstock F06)

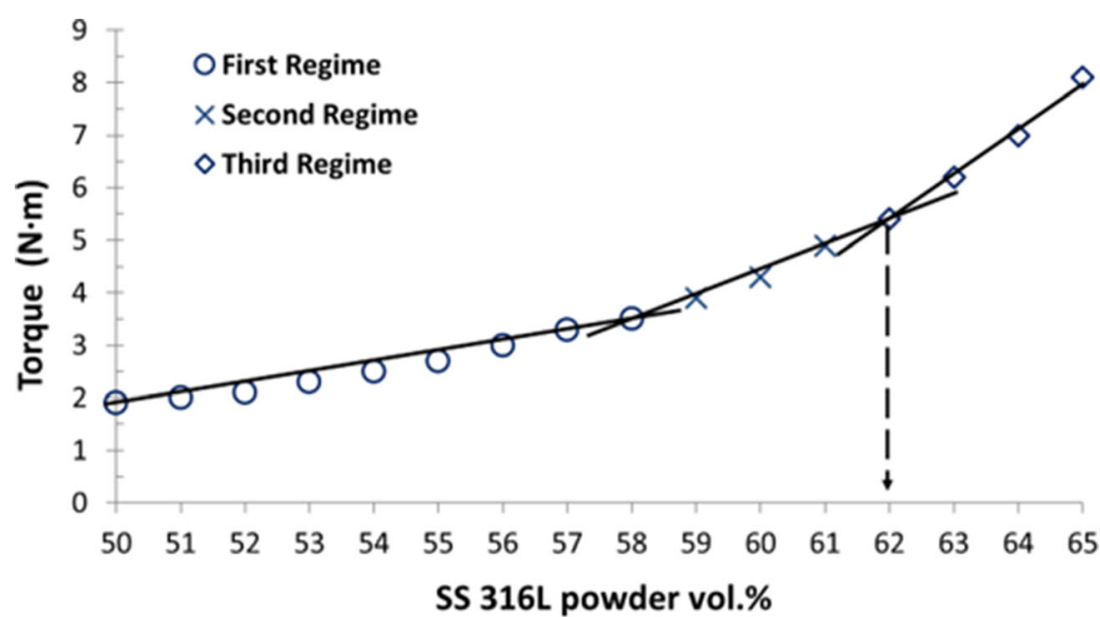


Fig. 8 Mixing torques (F01-F05) as a function of time $(Y<X$ vol.\%.); Stage 1, only binder addition; Stage 2, feedstock with additive addition. F01 is the standard feedstock without additives
F01 - SS 316L + M1

F02 - SS 316L + M1 + TPE(Y vol.\%)

- F03 - SS 316L + M1 + TPE(X vol.\%) + S(5 vol.\%)

A $\mathrm{F} 04-\mathrm{SS} 316 \mathrm{~L}+\mathrm{M} 1+\mathrm{TPE}(\mathrm{X}+5 \mathrm{vol} . \%)+\mathrm{S}(5 \mathrm{vol} . \%)$

- F05 - SS 316L + M1 + TPE(X+10 vol.\%) + S(5 vol.\%)

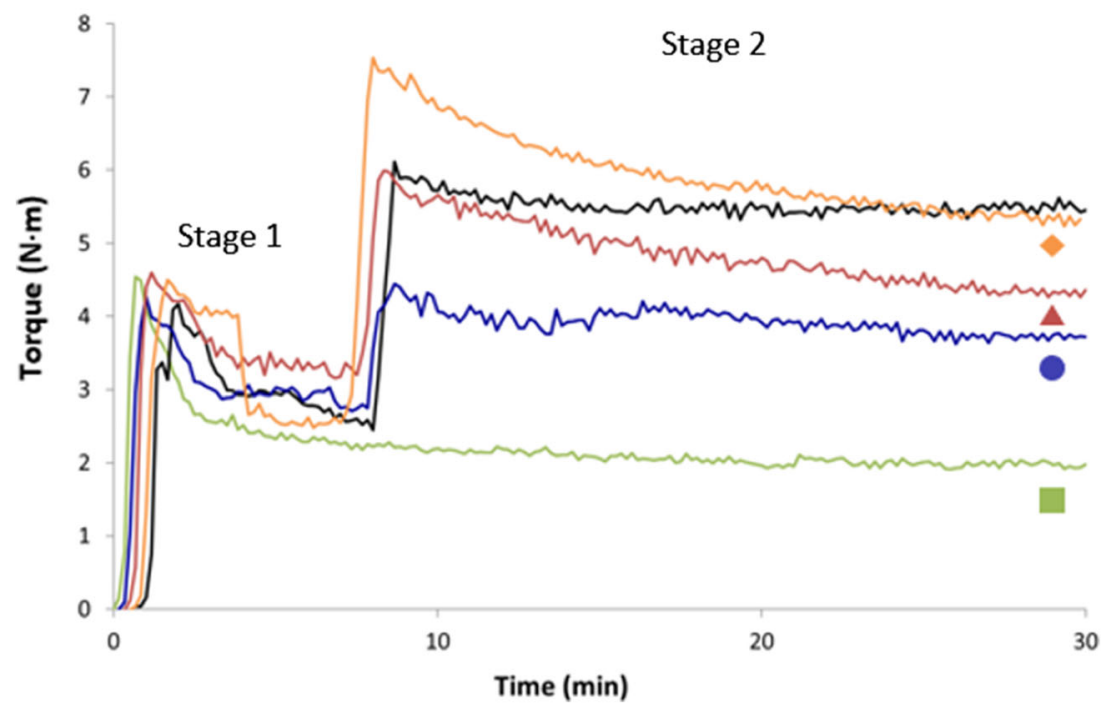

However, as previously mentioned, flexibility is one of the major characteristics of MEX filaments. For this reason, the backbone, surfactant, and plasticizer content were optimized. To select the best feedstock composition, two different approaches were considered: the addition of TPE + surfactant (S) and the addition of TPE + plasticizer (P).

Figure 8 shows the impact of the additive composition on the final torque value at the end of $30 \mathrm{~min}$. F01 is a feedstock
Fig. 9 F01 and F06-F08 mixing torques as a function of time $(W<$ $X$ vol.\%); Stage 1, only binder addition; Stage 2, feedstock with additive addition. F01 is the standard feedstock without additives
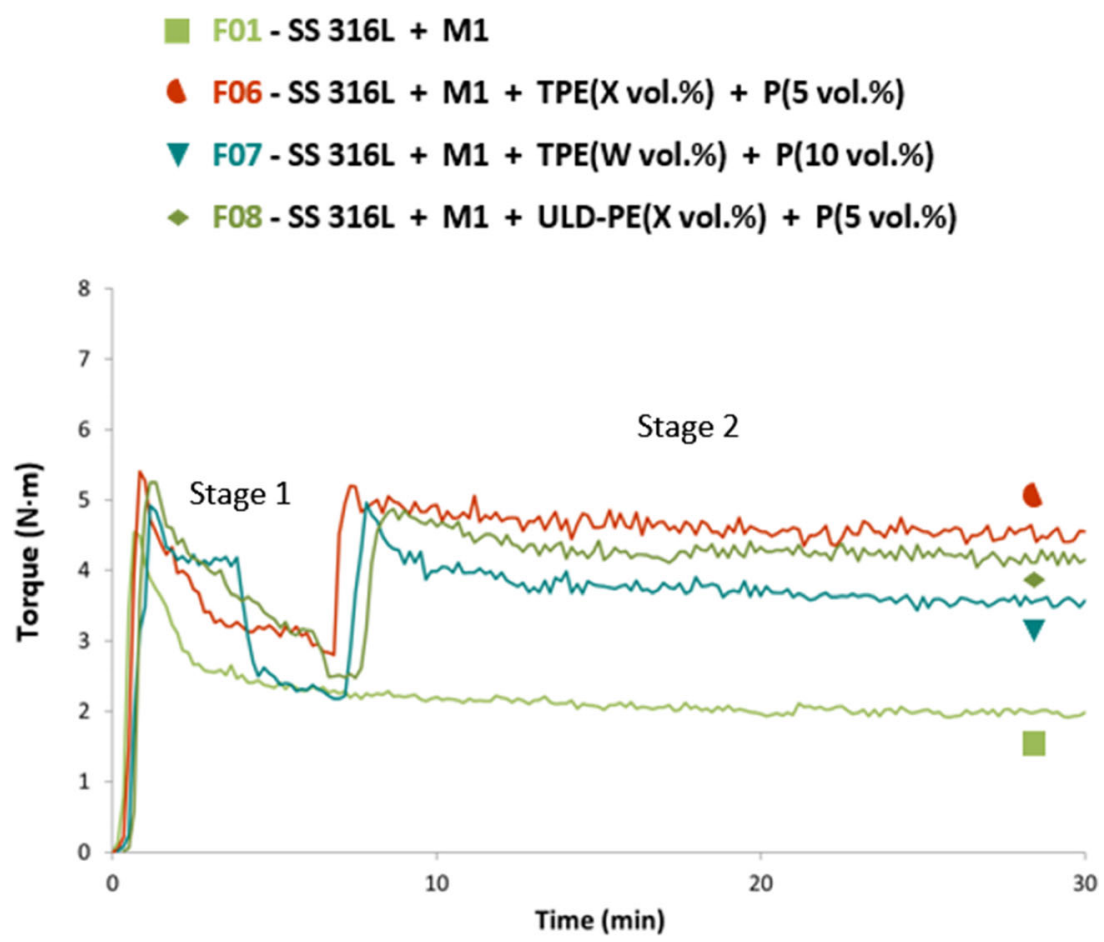
Fig. 10 Torque of the F03A and F03 mixtures as a function of time; Stage 1, only binder addition; Stage 2, feedstock with additive addition

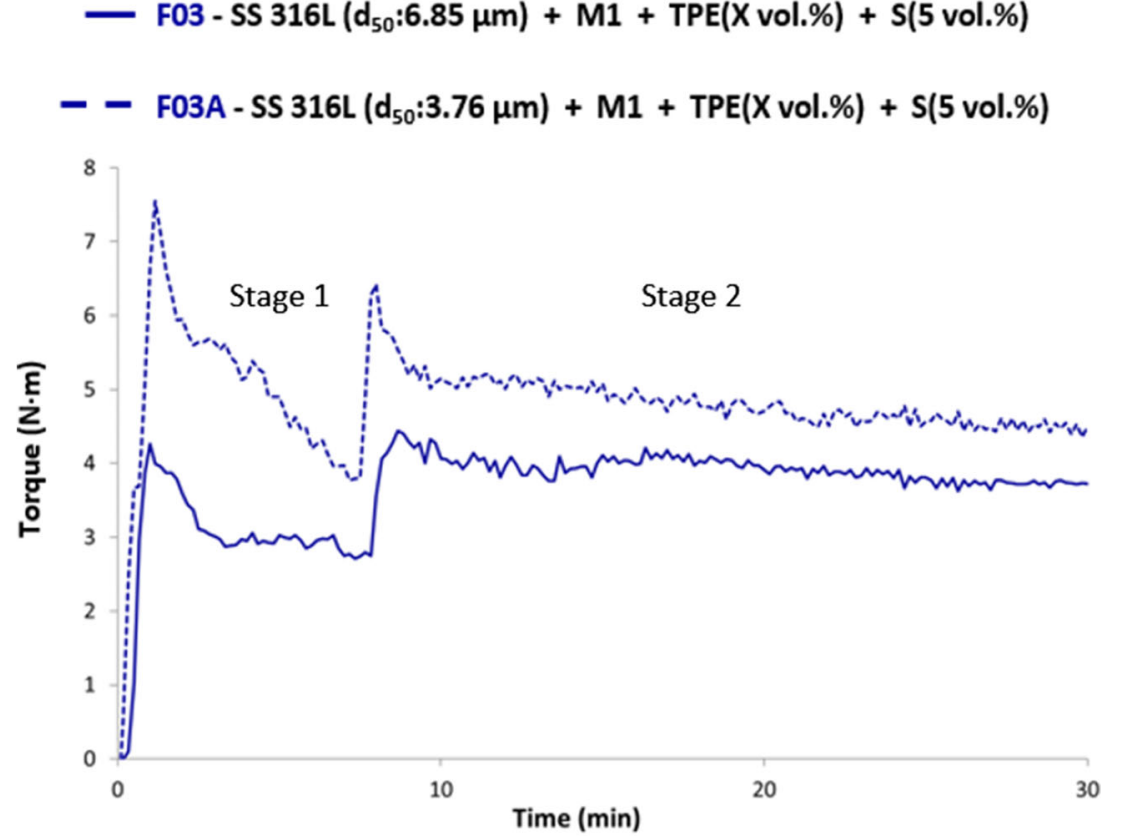

used in PIM, where there are no concerns about flexibility. In addition to promoting filament flexibility, TPE has a negative impact on the rheological behaviour of the feedstock. To overcome this issue, a surfactant $(\mathrm{S})$ was added. Among the feedstocks in Fig. 8, F03 (blue curve) showed the most promising behaviour (close to 4 N.m).

Although the selected surfactant, stearic acid (SA), clearly reduced the feedstock torque, other mixtures were studied to possibly replace it owing to the difficulty of fully removing it during debinding. Other work reported that SA requires raising the debinding temperature from 600 to $700{ }^{\circ} \mathrm{C}[30]$. Thus, $\mathrm{SA}$ was replaced with a plasticizer $(\mathrm{P})$, which also acts as a rheological modifier with the advantage that it promotes filament flexibility.

Figure 9 shows the different torque values for the remaining studied feedstocks (F06-F08). F06 had a final torque (4.6 $\mathrm{N} \cdot \mathrm{m})$ that was higher than that of F07 $(3.6 \mathrm{~N} \cdot \mathrm{m})$ due to its high TPE content. Comparing the feedstocks with the same vol.\% of all constituents (F03, F06, and F08), the addition of the surfactant (F03) had a larger influence on the final torque value than a plasticizer (F06 and F08), as expected. However, the plasticizer boosts filament flexibility, which is a very important requirement.
The feedstock F08, which had the composition as F06 except the TPE was replaced by ULD-PE, had a lower torque value, but it was still higher than the feedstock with SA (F03). Based on torque values of the feedstocks, F06-F08 seem to be suitable for use in MEX.

\subsubsection{Influence of metal powder particle size}

To evaluate the influence of the SS $316 \mathrm{~L}$ powder particle size on the rheological behaviour of the feedstock, two mixtures with the same vol.\% of SS 316 and additives but different particle sizes were compared: F03A and F03 with $d_{50}=3.76 \mu \mathrm{m}$ and $d_{50}=6.85 \mu \mathrm{m}$, respectively (Fig. 10). The finer particle size led to a higher final mixing torque compared with that of F03. For this reason, powder with $d_{50}=3.76 \mu \mathrm{m}$ was not selected for the studied feedstocks. This is an expected behaviour as small particles have a high specific surface area of contact, which promotes high interparticle friction [35].

Table 6 summarizes the average of ten torque values for each of the different feedstocks.

Table 6 Torque values of different feedstocks

\begin{tabular}{|c|c|c|c|c|c|c|c|c|c|}
\hline & F01 & F02 & F03 & F04 & F05 & F06 & F07 & F08 & F03A \\
\hline Torque [N.m] & $2.0 \pm 0.04$ & $5.5 \pm 0.07$ & $3.7 \pm 0.03$ & $4.3 \pm 0.04$ & $5.3 \pm 0.06$ & $4.5 \pm 0.07$ & $3.6 \pm 0.05$ & $4.2 \pm 0.07$ & $4.6 \pm 0.07$ \\
\hline Backbone content & - & $Y$ & $X$ & $X+5$ & $X+10$ & $X$ & $W$ & $X$ & $X$ \\
\hline $\mathrm{S}^{\dagger}$ or $\mathrm{P}^{*}($ vol. $\%)$ & - & - & 5 & 5 & 5 & 5 & 10 & 5 & 5 \\
\hline
\end{tabular}


Fig. 11 Spooled filament from feedstock F06
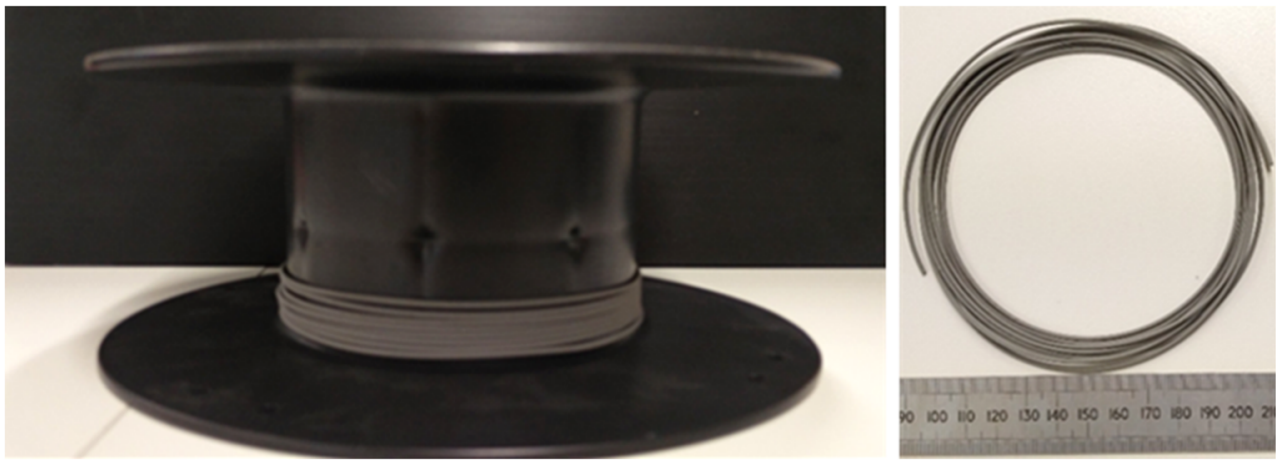

\subsection{Filaments}

\subsubsection{Green filament production}

In this study, the filament was not spooled by an automatic system. To avoid filament diameter deviations due to gravity action, a constant height between the extruder nozzle and the table was preserved for all formulations.

Standard filament (powder and binder, F01) was too brittle to spool. TPE addition resulted in the highest final torque value $(5.5 \mathrm{~N} . \mathrm{m})$ in mixture F02 curve. Also, the torque profile is the most unstable, because the dispersion of powder
Fig. 12 Cross-section fracture surfaces of filaments F01, F03, F06, and F08
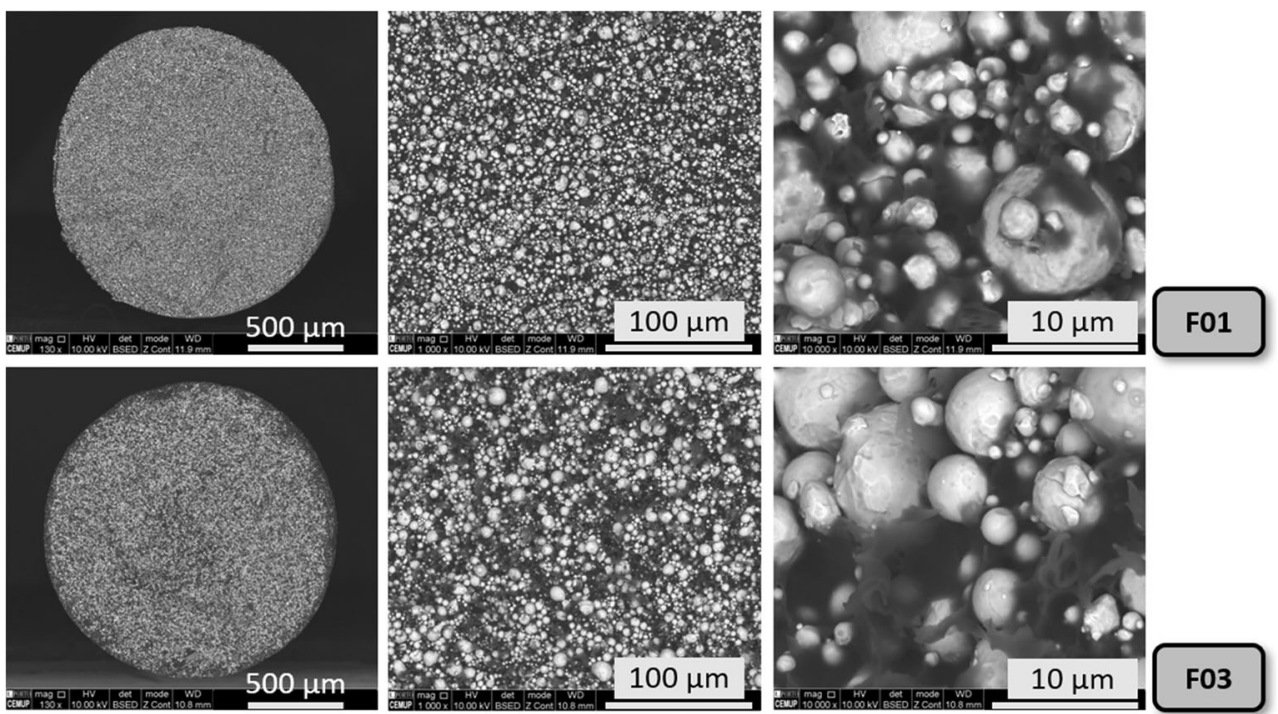

F03
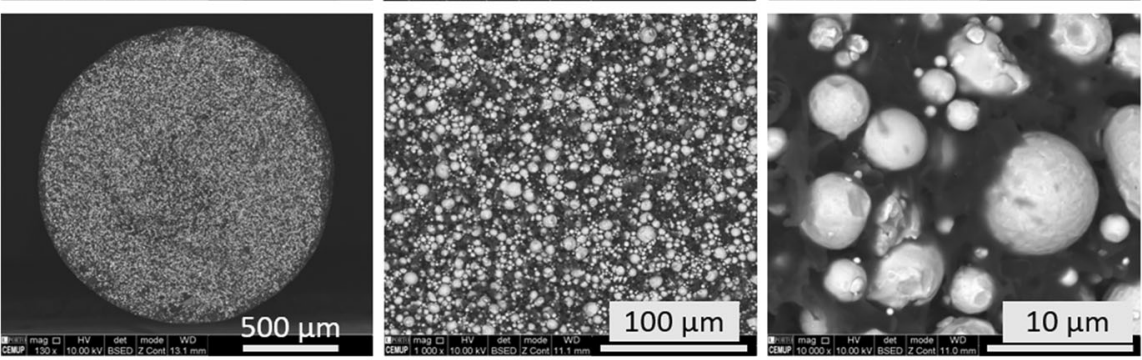

F06
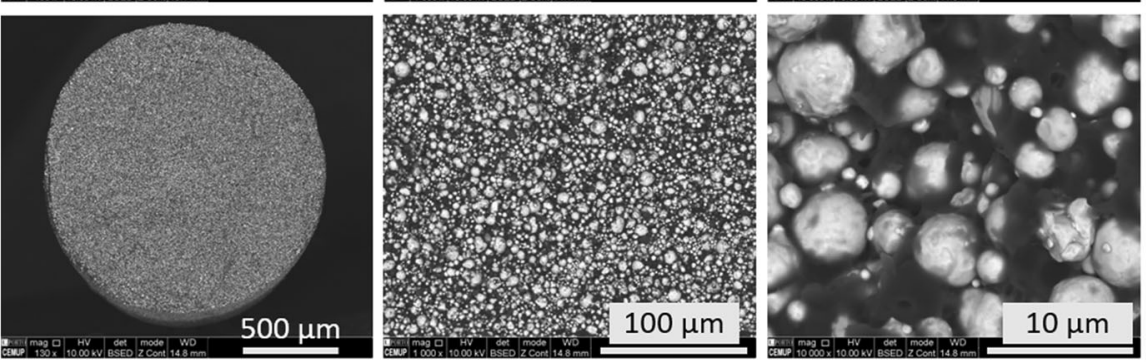

F08 

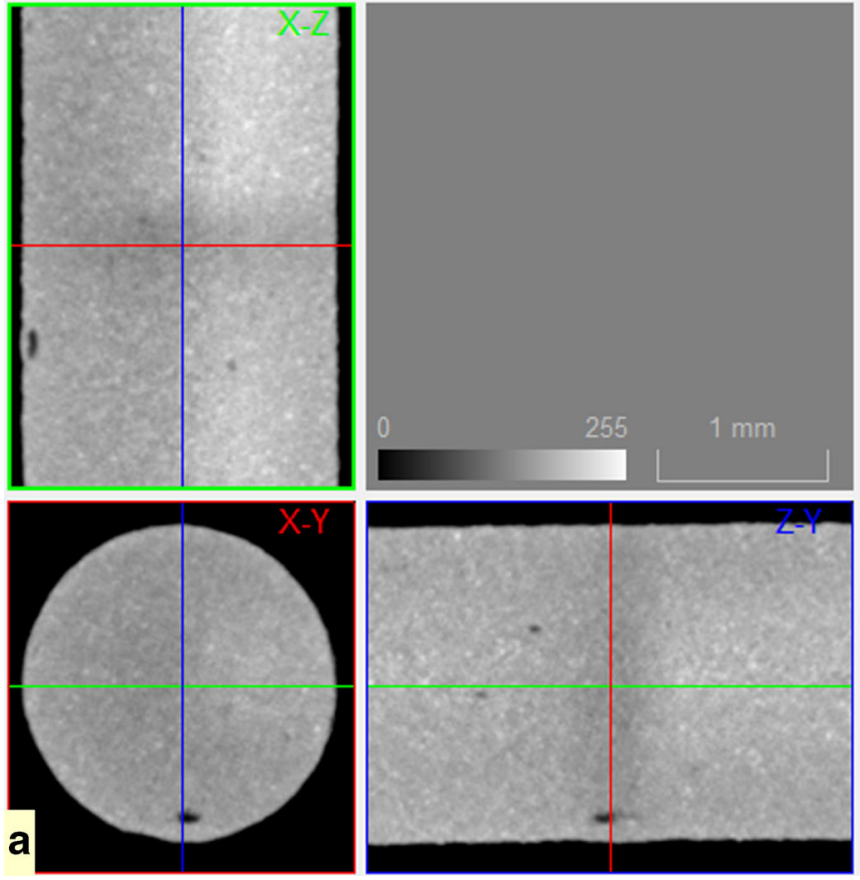

Fig. 13 Micro-CT of the a green filament F06 and b sintered filament F06

particles is more problematic in this binder. Thus, F02 was not extruded in a filament form. The other feedstocks (powder, binder, and additives) could be spooled (F03, F04, F05, and F08) but with a higher curvature than those of F06 and F07 (Fig. 11). It must be emphasized that the best filaments were those resulting from feedstocks with plasticizer and torque close to $5.0 \mathrm{~N} \cdot \mathrm{m}$.

\subsubsection{Characterization}

3.2.2.1 Homogeneity SEM observations of the filament crosssection shown that filament feedstocks without TPE (F01 and F08) appeared to be more homogeneous than the others (F03 and F06, Fig. 12), but their flexibility was poor. F03 and F06 $(=\mathrm{M} 1+\mathrm{TPE}+\mathrm{S} / \mathrm{P}$ vol. $\%)$ were quite similar regarding the homogeneity of the distribution of metallic powder. A large powder particle distance in the feedstocks improves flexibility but decreases density. Thus, considering these two features (filament flexibly and interparticle distance), a homogenous powder distribution is crucial, and a suitable balance between these features is required for the success of MEX.

Micro-CT analysis can be an effective solution for assessing filament homogeneity without fracture, which can modify the defect distribution on the observed volumes. Micro-CT was performed in a representative cross-section of filament F06 in the green and sintered states (Fig. $13 \mathrm{a}$ and b, respectively). It can be noted that the green filament (extruded feedstock in filament form, not subject to any subsequent processing step) presents a high density and consistent diameter throughout its section, reiterating the mechanical behaviour
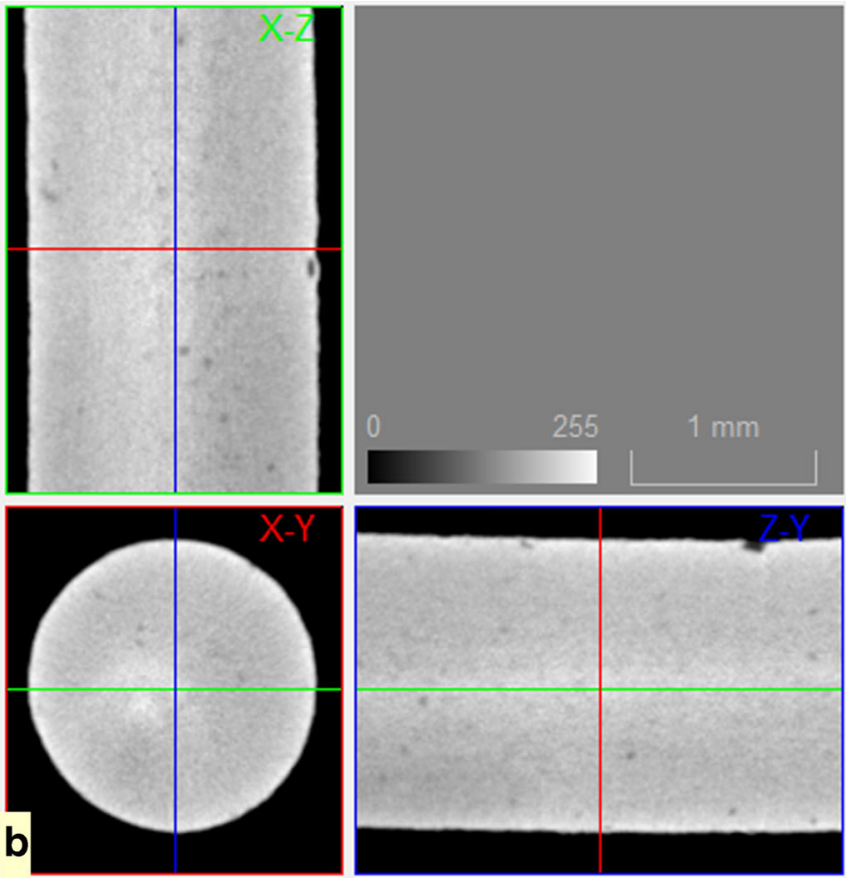

- green filament with the highest homogeneity

results (cf. 3.2.2.3). The observed residual pores seem to follow the extrusion direction (Fig. 13a, $X-Z$ and $Z-Y$ section), suggesting that the defects may occur in the extrusion process, resulting in elongated pore geometry. Nevertheless, the sintered filament shows that a sintered part with consistent density, with no persistent porosity caused by debinding, is still achievable, indicating that resulting porosity in final parts may be connected to printing parameters.

3.2.2.2 Structure The X-ray diffractograms (Fig. 14) show the evolution from SS 316L powder to the green and sintered filament. As referred, the austenitic powder, owing to its preparation technique, besides austenite (ICDD 33-0397), presents a ferrite/martensite phase (ICDD 87-0722-Fig. 3). This one increases, as expected, due to the deformation of powders

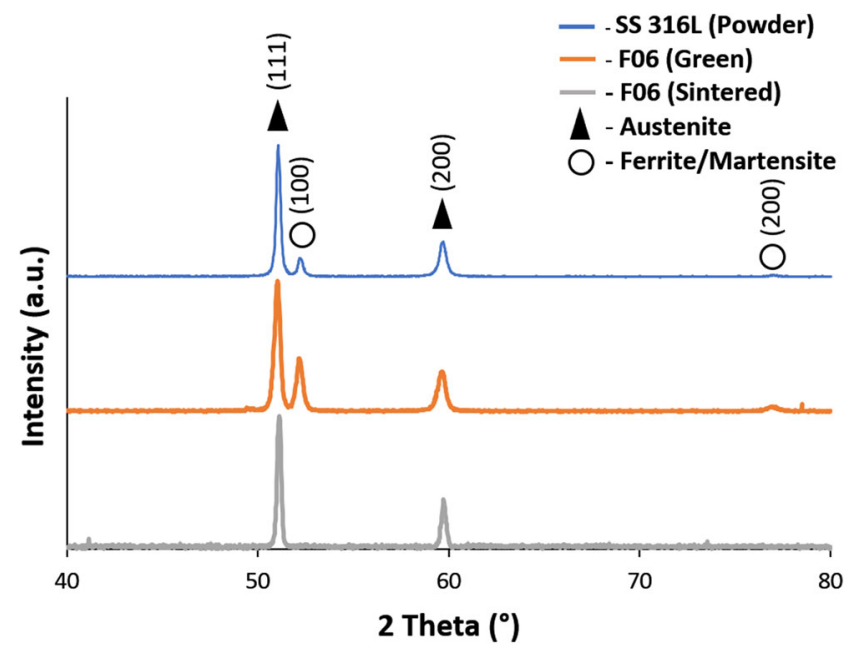

Fig. 14 X-ray diffraction of the sintered filament F06 
Fig. 15 Deflection at break (\%) and $E_{\text {flex }}$ of filaments F01 and F03-F08
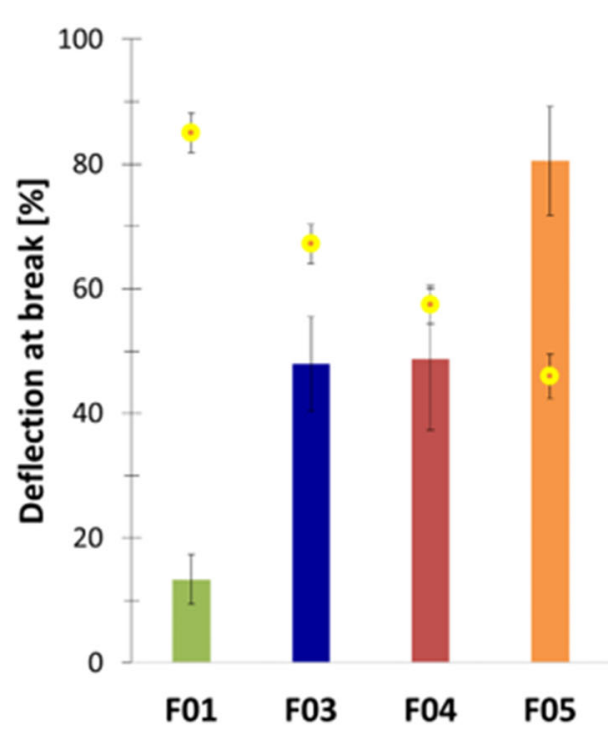

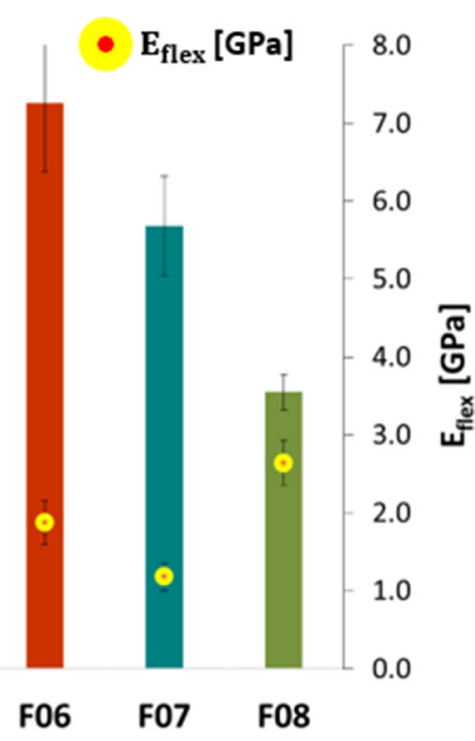

during its extrusion (Fig. 14) [36]. However, after sintering, the X-ray diffractogram shows only constituted by the austenitic phase, avoiding a post heat treatment, required in other additive processes.

3.2.2.3 Mechanical behaviour The deflection at rupture (\%) and flexural modulus of elasticity $\left(E_{\text {flex }}\right)$ was measured by three-point bending tests (Fig. 15). Each value in the figure is the average of five tests. These results, together with the previous torque rheometry study, allowed for selecting the most promising filament feedstocks regarding green processability.

The filament from feedstock F01, without additives, was the most brittle (13\%). With the incremental addition of TPE to feedstocks F03-F05, the maximum deflection of the filaments increased. Comparing filaments F03 and F06 (equal vol.\% of organic constituents), the replacement of the surfactant with a plasticizer improved the flexibility. A reduction in deflection from F06 (91\%) to F07 (71\%) was noticeable. F07
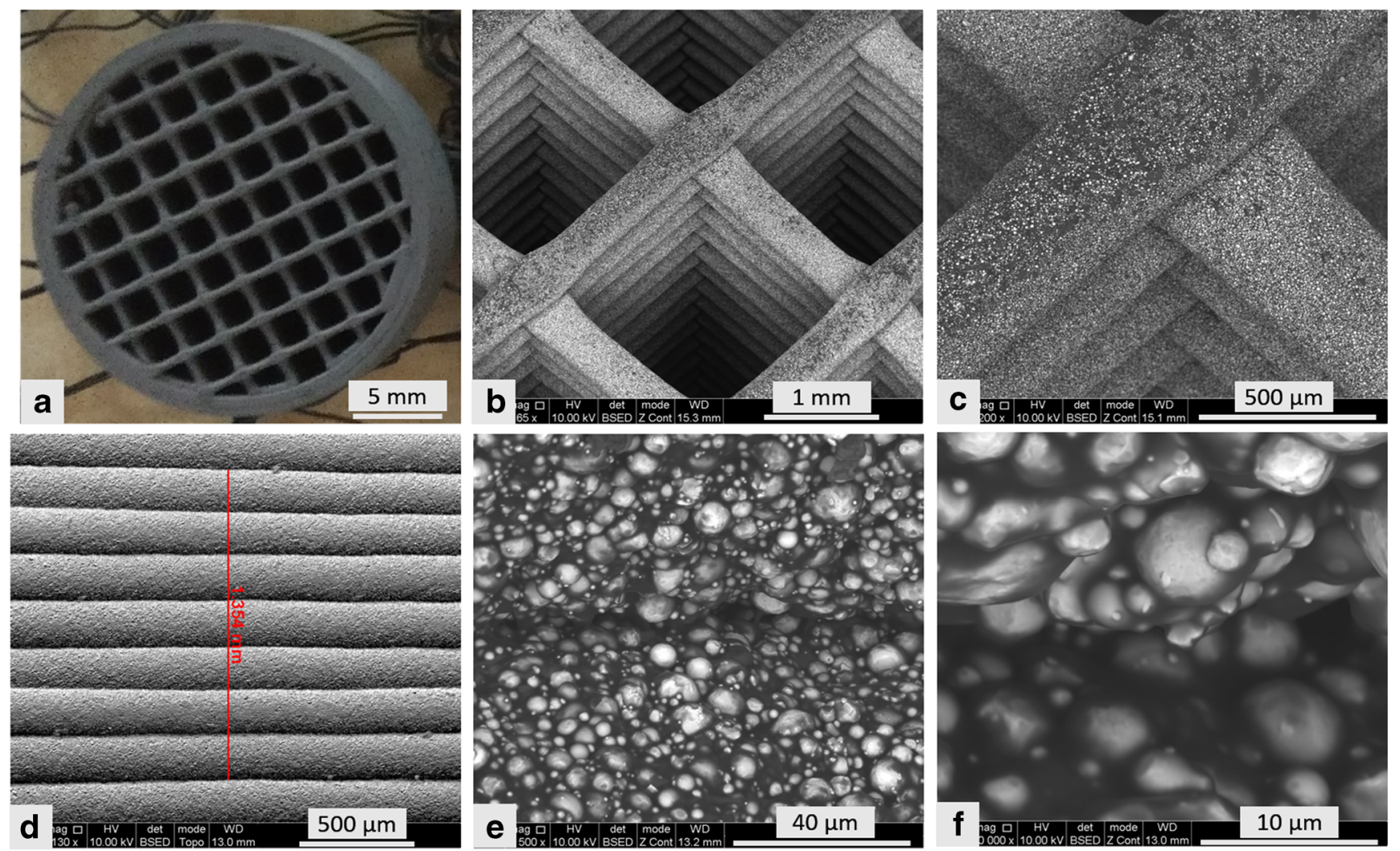

Fig. 16 Morphological analysis of the F06 green part: a, b, and $\mathbf{c}$ top views; $\mathbf{d}$, e, and $\mathbf{f}$ side views 
Table 7 FVM part dimensions (before and after sintering)

\begin{tabular}{llllll}
\hline & \multicolumn{2}{l}{ Height $(\mathrm{mm})$} & & \multicolumn{2}{l}{ Diameter $(\mathrm{mm})$} \\
\cline { 2 - 3 } \cline { 5 - 6 } \cline { 5 - 6 } & Green & Final part & & Green & Final part \\
\hline Measurement 1 & 7.2 & 6.2 & & 19.7 & 16.5 \\
Measurement 2 & 7.2 & 6.2 & & 19.7 & 16.5 \\
Mean & 7.2 & 6.2 & & 19.7 & 16.5 \\
Shrinkage (\%) & 13 & & & 16 & \\
\hline
\end{tabular}

had the highest additive content and, consequently, less TPE in the feedstock. F08 had ULD-PE instead of TPE. The reduction in the F08 filament flexibility (44\%) is more obvious compared to that of F06, which had the same additive, a plasticizer. In fact, filament from feedstock F08 was not used to produce the green parts because it was brittle, despite its promising mixing torque $(4.2 \mathrm{~N} \cdot \mathrm{m})$.

The $E_{\text {flex }}$ results of F07 and F08 were not expected, taking into account the relationship between the maximum deflection at break and the $E_{\mathrm{flex}}$ of the remaining filaments. This can be attributed to several factors, including porosity and the nonhomogeneous feedstock mixture. Similar behaviour was also reported by another study [19].

\subsection{Proof of concept}

The printability of the spoolable filaments (F03-F08) was studied. Filaments with the same surfactant (SA) but different TPE content (F03 and F04) were successfully printed. F05 was not printable owing to its high torque value, which was promoted by the high amount of TPE (vol.\%). F08 was too brittle to be printable, although within optimal mixture torque range. F06 and F07 shown the best printing behaviour.
Table 8 FVM part infill evaluation (before and after sintering)

\begin{tabular}{llllllll}
\hline & Measurement & \multicolumn{7}{c}{ Distance (mm) } \\
\cline { 3 - 7 } & & 1 & 2 & 3 & 4 & 5 & 6 \\
\hline \multirow{2}{*}{ Green } & Direction 1 & 1.6 & 1.6 & 1.6 & 1.6 & 1.6 & 1.6 \\
& Direction 2 & 1.6 & 1.6 & 1.6 & 1.6 & 1.5 & 1.7 \\
\multirow{2}{*}{ Final } & Direction 1 & 1.3 & 1.3 & 1.3 & 1.3 & 1.3 & 1.3 \\
& Direction 2 & 1.3 & 1.3 & 1.3 & 1.3 & 1.2 & 1.4 \\
\multirow{2}{*}{ Shrinkage (\%) } & 19 & 18 & 19 & 19 & 19 & 19 \\
\hline
\end{tabular}

The filament with the best mechanical characteristics (F06) was used to produce a part consisting of an infill pattern extrusion lines $(0.4 \mathrm{~mm})$ in a grid form and a two-perimeter exterior. Figure 16 shows different details of the green part (top and side views) built from the selected filament. Figure $16 \mathrm{~b}$ shows that a single extrusion line is geometrically reliable (not considering the flat zones due to superposition of lines), indicating that a filament with consistent diameter and no relevant ovality was achieved, since this would otherwise affect the extrusion behaviour. Figure 16d shows that the postdeposited layer thickness was almost the same as the $3 \mathrm{D}$ de$\operatorname{sign}(0.2 \mathrm{~mm})$.

For the highest magnifications (Fig. 16e and f), it is obvious that a critical zone exists: interface layers. These bonding zones could have a significant role in the occurrence of defects in the final parts. For this reason, further detailed studies must be performed to understand their influence on the properties of the final metallic part.

The green shrinkage and warpage were evaluated by FVM. The measurements of the external diameter and height were performed in two opposite locations. From the results (Table 7), a slight variation in the green dimensions was noticeable when compared with the 3D model (ø $20 \mathrm{~mm}$ and a height of $7.0 \mathrm{~mm}$ ).
Fig. 17 FVM part B infill evaluation: a green and $\mathbf{b}$ sintered part

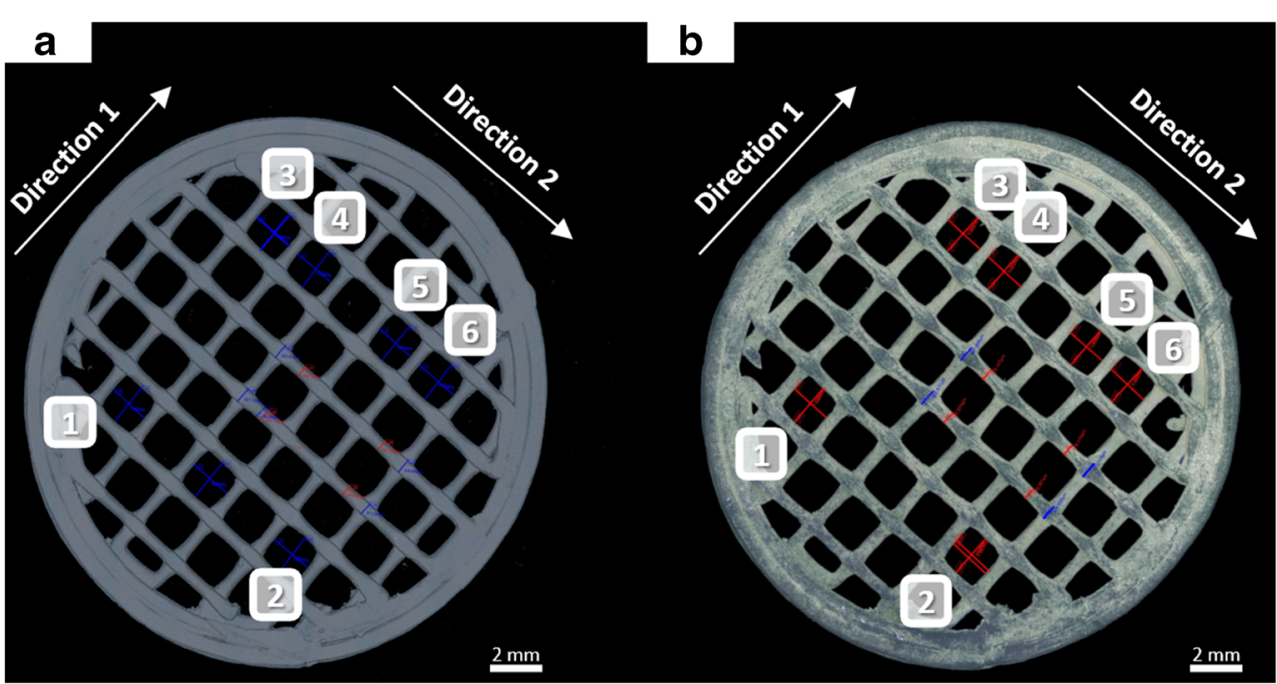


Fig. 18 Microhardness of the proof of concept $(\mathrm{PoC})$ part in comparison with other data $[30$, $37,38]$

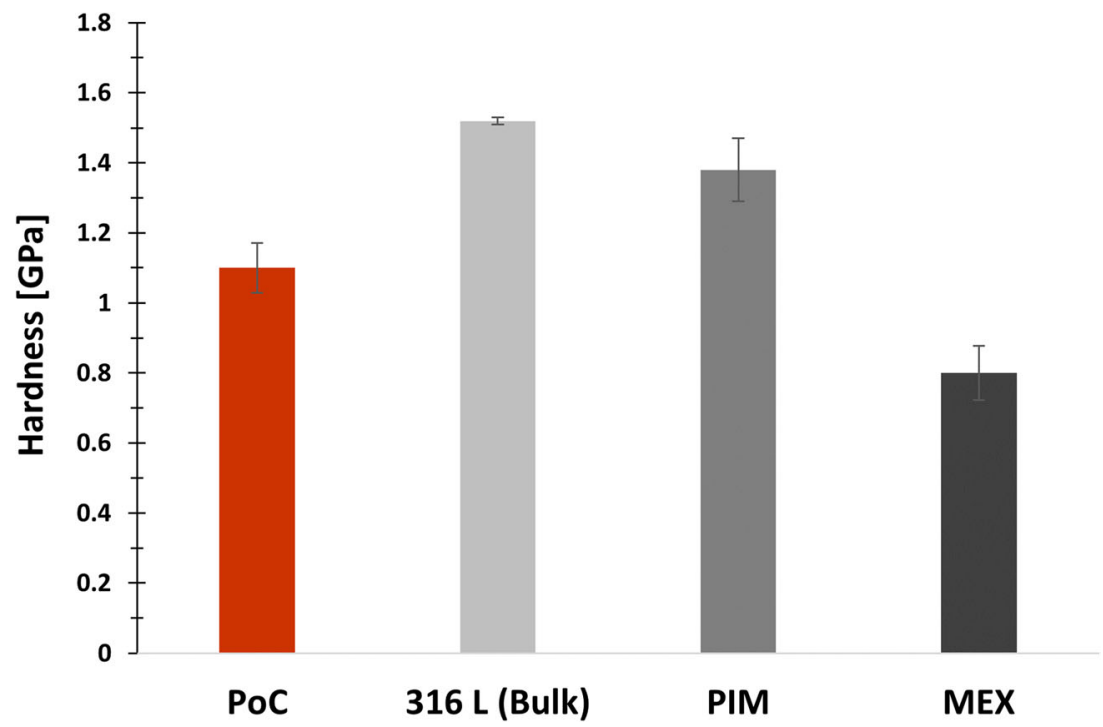

There was a slight variation in the shrinkage between the $X Y$ plane and the $Z$-axis. This deviation was also reported in other studies and can be associated with the build strategy (orientation of the layers) [4, 17]. The diameter shrinkage was, on average, $2.5 \%$ higher than in the build direction. Because the amount of shrinkage is affected by processing parameters and feedstock characteristics, a detailed comparison must be avoided without further investigation.

The geometry of the green infill (40\%) and shrinkage was also evaluated by FVM (Fig. 17). Green part infill was printed with high accuracy because the interlayer distance (measurement 1 to 6$)$ was constant in both measured directions $\left(0^{\circ}\right.$ and $90^{\circ}$ ) (Fig. 17a and Table 8). After sintering, accuracy was not affected (Fig. 18b and Table 8).

In comparison with the previous FVM measurements, the part infill (width $=$ nozzle $\varnothing, 0.4 \mathrm{~mm}$ ) shrinkage was higher $(\sim 19 \%$, Table 8$)$ than in the other directions (13$17 \%$, Table 7). The $40 \%$ infill configuration can largely affect the shrinkage of the part relative to the $X Y$ directions. This is similar to what occurs in PIM parts for different thicknesses.

The microhardness value of the part developed as a proof of concept (PoC, Fig. 18) was $1.1 \mathrm{GPa}$, which is higher than those of other studies for the same material on MEX [37]. Nevertheless, the microhardness values are lower than those measured in a PIM made from SS 316L and a bulk steel part $[30,38]$.

\section{Conclusions}

High-quality filaments for metallic MEX can be attained by optimization of different manufacturing steps: feedstocks production (metallic powder, binder, and additives), evaluation of extrudability (torque $<4.0-4.5 \mathrm{~N} \cdot \mathrm{m}$, supported by other rheological studies), debinding, and sintering. In the filament feedstocks, the main challenges are to reach the highest metallic powder content with good extrudability and a suitable ratio between stiffness and flexibility. Some filaments, without surfactant/plasticizer or with different additive contents, are unsuitable due to the difficulty to be extruded, owing to their high mixing torque.

From the extruded feedstocks, the selected case study shows that, for the filament constituted by SS 316L + M1 + $\mathrm{TPE}+\mathrm{P}$, the best green mechanical characteristics are attained due to the excellent homogenization of the mixing, demonstrated by micro-CT. Moreover, the best filament, after debinding and sintering, continues to show excellent performance, concerning defects (porosity) and consequently, the best flexural modulus, and deflection at break, assuring an excellent MEX processability. In the case of austenitic steel powders, the austenite phase is the only phase present, avoiding other costly post heat treatments. In conclusion, this study promotes a supported methodology for producing filaments for MEX and promotes the possibility to make 3D parts/systems or devices whatever the metallic powders selected, without commercial market offer dependence.

Author contribution Fábio Cerejo: investigation, conceptualization, methodology, visualization, and writing - original draft preparation. Daniel Gatões: Micro-CT investigation and methodology, writing, and review. Teresa Vieira: supervision, conceptualization, and review and editing.

Funding This work was supported by the European Regional Development Fund (ERDF) under the Portuguese program, Programa Operacional Factores de Competitividade (COMPETE) [grant agreement No. POCI-01-0247-FEDER-024533]; and this research is sponsored by 
FEDER funds through the program COMPETE — Programa Operacional Factores de Competitividade - and by national funds through FCT, Fundação para a Ciência e a Tecnologia, under the project UIDB/00285/2020.

Data availability Data will be available upon request.

\section{Declarations}

Ethical approval Not applicable.

Consent to participate Not applicable.

Consent for publication Not applicable.

Conflict of interest The authors declare no competing interests.

Open Access This article is licensed under a Creative Commons Attribution 4.0 International License, which permits use, sharing, adaptation, distribution and reproduction in any medium or format, as long as you give appropriate credit to the original author(s) and the source, provide a link to the Creative Commons licence, and indicate if changes were made. The images or other third party material in this article are included in the article's Creative Commons licence, unless indicated otherwise in a credit line to the material. If material is not included in the article's Creative Commons licence and your intended use is not permitted by statutory regulation or exceeds the permitted use, you will need to obtain permission directly from the copyright holder. To view a copy of this licence, visit http://creativecommons.org/licenses/by/4.0/.

\section{References}

1. Alcácer V, Cruz-Machado V (2019) Scanning the Industry 4.0: a literature review on technologies for manufacturing systems. Eng Sci Technol Int J 22:899. https://doi.org/10.1016/j.jestch.2019.01. 006

2. Dilberoglu UM, Gharehpapagh B, Yaman U, Dolen M (2017) The role of additive manufacturing in the era of Industry 4.0. Proc Manufact 11:545. https://doi.org/10.1016/j.promfg.2017.07.148

3. Additive Manufacturing Wohlers Report 2018 shows rise in metal additive manufacturing. https://www.additivemanufacturing. media/news/wohlers-report-2018-shows-rise-in-metal-additivemanufacturing.

4. Lieberwirth C, Harder A, Seitz H (2017) Extrusion based additive manufacturing of metal parts. JMEA 7. https://doi.org/10.17265/ 2159-5275/2017.02.004

5. Gong H, Crater C, Ordonez A, Ward C, Waller M, Ginn C (2018) Material properties and shrinkage of 3D printing parts using Ultrafuse Stainless Steel 316LX Filament. MATEC Web Conf 249:01001. https://doi.org/10.1051/matecconf/201824901001

6. Thompson Y, Gonzalez-Gutierrez J, Kukla C, Felfer P (2019) Fused filament fabrication, debinding and sintering as a low cost additive manufacturing method of $316 \mathrm{~L}$ stainless steel. Addit Manufact 30:100861. https://doi.org/10.1016/j.addma.2019. 100861

7. (2020) Making additive manufacturing sustainable: ask the right question. tct MAG 28:24-25

8. Lingqin X, Guang C, Luyu Z, Pan L (2020) Explore the feasibility of fabricating pure copper parts with low-laser energy by selective laser melting. Mater Res Express 7:106509. https://doi.org/10. 1088/2053-1591/abbd08
9. Ikeshoji T-T, Nakamura K, Yonehara M, Imai K, Kyogoku H (2018) Selective laser melting of pure copper. JOM 70:396-400. https://doi.org/10.1007/s11837-017-2695-x

10. Godec D, Cano S, Holzer C, Gonzalez-Gutierrez J (2020) Optimization of the $3 \mathrm{D}$ printing parameters for tensile properties of specimens produced by fused filament fabrication of $17-4 \mathrm{PH}$ Stainless Steel. Materials 13:774. https://doi.org/10.3390/ ma13030774

11. ISO/ASTM Additive manufacturing - General principles - terminology (ISO/ASTM DIS 52900:2018)

12. Ziaee M, Crane NB (2019) Binder jetting: a review of process, materials, and methods. Addit Manufact 28:781-801. https://doi. org/10.1016/j.addma.2019.05.031

13. Bai Y, Williams CB (2018) Binder jetting additive manufacturing with a particle-free metal ink as a binder precursor. Mater Des 11

14. Bai Y, Wagner G, Williams CB (2017) Effect of particle size distribution on powder packing and sintering in binder jetting additive manufacturing of metals. J Manuf Sci Eng 139:081019. https://doi. org/10.1115/1.4036640

15. Singh P, Balla VK, Tofangchi A, Atre SV, Kate KH (2020) Printability studies of Ti-6Al-4V by metal fused filament fabrication (MF3). Int J Refract Met Hard Mater 91:105249. https://doi. org/10.1016/j.ijrmhm.2020.105249

16. Danforth SC, Agarwala M, Bandyopadghyay A et al (1998) Solid freeform fabrication methods. 17

17. Gonzalez-Gutierrez J, Cano S, Schuschnigg S, Kukla C, Sapkota J, Holzer C (2018) Additive manufacturing of metallic and ceramic components by the material extrusion of highly-filled polymers: a review and future perspectives. Materials 11:840. https://doi.org/ 10.3390/ma1 1050840

18. M K Agarwala, Weeren, R. van, Bandyopadhyay, A., et al (1996) Fused deposition of ceramics and metals: an overview. In: International Solid Freeform Fabrication Symposium. Texas, USA, $p 8$

19. Kukla C, Duretek I, Schuschnigg S, Gonzalez-Gutierrez J (2016) Properties for PIM feedstocks used in fused filament fabrication. In: Proceedings of the World PM2016 Congress \& Exhibition. Hamburg, Germany, 9-13 October 2016, p 5

20. Gonzalez-Gutierrez J, Godec D, Kukla C et al (2017) Shaping, debinding and sintering of steel components via fused filament fabrication. Croatian Association of Production Engineering, Zagreb, pp 99-104

21. Burkhardt C, Freigassner P, Weber O et al (2016) Fused filament fabrication (FFF) of $316 \mathrm{~L}$ Green parts for the MIM process. In: Proceedings of the World PM2016 Congress \& Exhibition. EPMA, Hamburg, pp 9-13 October 2016

22. Andersen O, Riecker S, Studnitzky T et al (2018) Manufacturing and properties of metal parts made by fused filament fabrication. In: Euro PM2018 Proceedings. EPMA, Bilbao, Spain, 14 - 18 October 2018, pp 1-6

23. Kurose T, Abe Y, Santos MVA, Kanaya Y, Ishigami A, Tanaka S, Ito $H$ (2020) Influence of the layer directions on the properties of 316L stainless steel parts fabricated through fused deposition of metals. Materials 13:2493. https://doi.org/10.3390/ma13112493

24. Gloeckle C, Konkol T, Jacobs O, Limberg W, Ebel T, Handge UA (2020) Processing of highly filled polymer-metal feedstocks for fused filament fabrication and the production of metallic implants. Materials 13:4413. https://doi.org/10.3390/ma13194413

25. Nestle, Nikolaus, Hermant, Marie-Claire, Schmidt, Kris (2016) Mixture for use in a fused filament fabrication process. 40

26. German RM, Bose A (1997) Injection molding of metals and ceramics. Metal Powder Industry, Princeton

27. Vieira MT, Martins AG, Barreiros FM, Matos M, Castanho JM (2008) Surface modification of stainless steel powders for microfabrication. J Mater Process Technol 201:651-656. https:// doi.org/10.1016/j.jmatprotec.2007.11.162 
28. Ferreira TJ, Vieira MT (2017) Optimization of MWCNT - metal matrix composites feedstocks. Ciência Tecnol Mater 29:87-91. https://doi.org/10.1016/j.ctmat.2016.07.010

29. Carreira P, Cerejo F, Alves N, Vieira MT (2020) In search of the optimal conditions to process shape memory alloys (NiTi) using fused filament fabrication (FFF). Materials 13:4718. https://doi. org $/ 10.3390 / \mathrm{ma} 13214718$

30. Ferreira TJJ (2018) Microinjection moulding of austenitic stainless steel reinforced with carbon nanotubes, $\mathrm{PhD}$ Thesis. University of Coimbra

31. Tafti AA, Demers V, Majdi SM, Vachon G, Brailovski V (2021) Effect of thermal debinding conditions on the sintered density of low-pressure powder injection molded iron parts. Metals 11:264. https://doi.org/10.3390/met1 1020264

32. Cerejo F, Raimundo AM, Vieira MT, Barreiros FM (2019) Fused deposition of $\mathrm{WC}+\mathrm{Co}$ powder. EPMA, Maastricht Exhibition \& Congress Centre, Maastricht

33. Ferreira TJ, Vieira MT (2014) Behaviour of feedstocks reinforced with nanotubes for micromanufacturing. In: Euro PM 2014 Congr. Exhib. Proc. EPMA. The Messezentrum Salzburg, Austria

34. Dimitri C, Mohamed S, Thierry B, Jean-Claude G (2017) Influence of particle-size distribution and temperature on the rheological properties of highly concentrated Inconel feedstock alloy 718 . Powder Technol 322:273-289. https://doi.org/10.1016/j.powtec. 2017.08.049

35. Ibrahim MHI, Muhamad N, Sulong AB (2011) Rheological characterization of water atomised stainless steel SS316L for Micro MIM. Adv Mater Res 264-265:129-134

36. Kaleta J, Wiewiórski P, Wiśniewski W (2017) Investigation of martensitic transformation induced by cyclic plastic deformation in austenitic steels. In: Borek W, Tanski T, Brytan Z (eds) Austenitic Stainless Steels - New Aspects. InTech. https://doi.org/ 10.3390/ijerph14101126

37. Li JB, Xie ZG, Zhang XH, Zeng QG, Liu HJ (2010) Study of metal powder extrusion and accumulating rapid prototyping. Key Eng Mater 443:81-86. https://doi.org/10.4028/www.scientific.net/ KEM.443.81

38. Matweb (2019) SS 316L. http://www.matweb.com/search/ DataSheet.aspx ? MatGUID $=530144$ e 2752 b 4770 9a58ca8fe0849969. Accessed 15/02/2021

Publisher's note Springer Nature remains neutral with regard to jurisdictional claims in published maps and institutional affiliations. 